\section{Contra el técnico bárbaro: Remembranzas de una universidad humanista de Eduardo Morales Miranda*}

\begin{abstract}
Against the barbarian technician: Remembranzas de una universidad humanista of Eduardo Morales Miranda
\end{abstract}

Eduardo Morales Miranda, abre un rico campo de exploración histórico y sociocultural sobre los límites y las potencialidades de la singularidad biográfica para comprender la construcción de la institucionalidad universitaria en Chile y su complejo devenir en los espacios regionales. El propósito de este trabajo es analizar los escritos autobiográficos de Morales -triangulados con diversas fuentes escritas y orales- a partir de tres ejes de lectura: como epónimo generacional; como testimonio ideológico de las tensiones entre el Estado, el desarrollo regional y el pensamiento educativo, $\mathrm{y}$; como género, en cuanto caso inusual de "heterobiografía" en primera persona.

Palabras clave: autobiografía, memorias, Eduardo Morales Miranda, historia de las universidades en Chile, Universidad Austral de Chile.

\section{Abstract}

YANKo GonZÁLEZ ${ }^{* *}$

\section{Resumen}

El libro de memorias Remembranzas de una universidad humanista (2004) del Ex Rector Fundador de la Universidad Austral de Chile,

Parte de este artículo se basa en la investigación y prefacio a proyecto de reedición del libro Remembranzas de una Universidad Humanista del ex rector fundador de la Universidad Austral de Chile, Eduardo Morales Miranda. Dicho libro fue autoeditado originalmente en 2004 con un tiraje restringido.

** Instituto de Historia y Ciencias Sociales, Universidad Austral de Chile, Valdivia, Chile. Correo electrónico: ygonzale@uach.cl
The book of memories Remembranzas de una universidad humanista (2004) written by the former rector and founder of the Universidad Austral de Chile, Eduardo Morales Miranda, opens a rich field of historical and sociocultural exploration about the limits and potentials of the biographical uniqueness to understand the construction of the university institutionalism in Chile and its complex development in the regional areas. The purpose of this work is to analyze the autobiographical writings of Morales -triangulated with various written and oral sources- based on three lines of reading: as generational eponymous; as ideological testimony of tensions between the state, regional development and educational thoughts materialized in the country since the 
mid-twentieth century, and; as a genre, being an unusual case of "heterobiography" in first person.

Key words: autobiography, memories, Eduardo Morales Miranda, history of universities in Chile, Universidad Austral de Chile.

\section{Introducción}

En su provocador ensayo La ilusión biográfica, Pierre Bourdieu (1986) reaviva una antigua discusión en las ciencias humanas y sociales sobre la capacidad de las cadenas de experiencias individuales para comprender $\mathrm{y}$ representar la totalidad de lo social. En él, el intelectual francés impugna la extensa tradición y producción (auto)biográfica -y sus exégetascomo ejercicio infértil para dar cuenta de una época, las condiciones socioculturales explicativas de un colectivo o el propio devenir histórico. Los estilos o variantes individuales, defendía Bourdieu (1986), son producto de coerciones de un "campo" externo, estructural, que opera a través de condicionantes sociales, de las cuales las acciones humanas no son más que reflejos. De este modo -ejemplifica-, resulta imposible entender un trayecto del metro sin tener en cuenta la estructura de la red, es decir, la matriz de las relaciones objetivas entre las diferentes estaciones. Su tesis la defendió hasta el final, al punto que rotuló sus propias memorias biográficas (Bourdieu 2004) -publicadas póstumamente- como un "autoanálisis", en un intento por controlar la tentación de los posibles lectores de interpretar sus escritos como un documento generativo para explicar ficcional o factualmente lo que hizo, pensó o le rodeó como una práctica escogida en un proyecto libre (Cfr. Bourdieu 1997).
El entrevero, con alcances y consecuencias teóricas mayores, resulta pertinente para situar este corpus rememorativo del ex rector fundador de la Universidad Austral de Chile, Eduardo Morales, por cuanto éstas evidencian, como pocas (auto)biografías, la tensión entre el destino individual, sus determinaciones estructurales y, de sobremanera, la incidencia de ese destino en la elaboración de aquellas mismas determinaciones. Dicho de otro modo, estamos ante la capacidad de una vida no sólo para "retratar" una época o un proceso histórico regional -como una pieza que enriquece el cuadro de la emergencia de una universidad-, sino también, el poder, la agencia y la libertad de esa vida para alterar o construir decididamente esos procesos. Dicho poder, creemos, aparece con fuerza en esta vida puesta en escritura a través de estas reminiscencias: más que una excepcionalidad "normal" -como podría argüir Bourdieu-, resulta un punto de fuga que nos permite mucho más que enriquecer el cuadro: preguntarnos por la constitución del cuadro mismo.

En este sentido, no resulta casual que en la memoria oral de distintas generaciones de la comunidad universitaria, y aún más allá, de la ciudad de Valdivia y la región, persista un recuerdo de Morales situado en los límites de su singularidad. Desde aquellos que lo recuerdan llegando a uno de los primeros pensionados estudiantiles -"Vista Alegre"- a las 6:30 de la mañana para desayunar con los estudiantes y controlar la asistencia a clases ${ }^{1}$, pasando por los que lo evocan tomándose ilegalmente una servidumbre de paso (la actual Alameda de acceso) y plantando con sus propias fuerzas

Julio Flores, estudiante de Medicina Veterinaria (Cit. en Almonacid 2003). 
los álamos que la flanquean (Cfr. Araya 2011) "para levantar la vista al cielo antes de ingresar a los recintos universitarios" (Morales 2004: 128); hasta los que relatan la vez que Morales, apremiado por la aceptación del presupuesto para el siguiente año contable por parte de un renuente directorio, lanzó sorpresivamente a la mesa un conjunto de piedras sacadas de su bolsillo, planteándoles que en uno de los predios de la universidad se había encontrado oro como lo probaban los guijarros-, por lo que las preocupaciones de los honorables directores por los abultados gastos futuros, no tenían ya razón².

Esta singularidad se extiende, igualmente, en la memoria de los que narran la capacidad de persuasión del ex rector para con las autoridades del país ${ }^{3}$, para con los que se opusieron tenazmente a sus empeños por fundar la Universidad Austral de Chile $^{4}$, y para con los que le atribuyen afirmaciones sentenciosas, como "que la sociedad está integrada por ganapanes y ganafortunas y en muy pocos casos por ciudadanos a quienes les importa hacer bien lo que les corresponde

Esta memoria -y sus versiones- fue traspasada oralmente por un académico y miembro fundador de la Universidad Austral. Según el relato -con cariz de fábula-, el presupuesto fue aprobado.

3 En un viaje para buscar apoyo parlamentario -cuenta el ex académico Raúl Jara R.-, el Alcalde de Valdivia Max Frick le presenta a Morales al entonces Presidente de la Cámara de Diputados, Juan Antonio Coloma. "A los pocos minutos el Alcalde valdiviano pudo observar cómo el Dr. Morales tenía asido por las solapas al Presidente de la Cámara de Diputados, de contextura gruesa, y lo remecía mientras le pedía [que] otorgara un crédito por 40 mil escudos para la nueva Universidad. Lo consiguió, merced a haber zarandeado a una de las más altas autoridades del país en ese momento" (Van de Maele 1996: s/p).

Una variante de las muchas que circulan en la memoria ora (relatada por una ex funcionaria y partícipe cercana de su gestión) sobre la obstinación de Morales por crear y poner en marcha la universidad, es la existencia de un listado exhaustivo de sus principales detractores, a los que visitaba de improviso en sus casas para encararlos y convencerlos de que se sumaran a su causa. para contribuir e integrar una comunidad sólida"5, tributarias de un "hombre de acción" y no de "contemplación" -como caracterizara Leopoldo Castedo a Morales (Van de Maele 1996)- que "al compás de un ritmo endiablado no descansaba jamás, ni tampoco dejaba respirar a quienes lo acompañaban"6. Ciertas o no, dichas memorias interesan menos por su verdad que por sus consecuencias: la configuración, la fijación y la reproducción de una épica fundacional sintetizada en un actor que encarna y resume los ímpetus y trastornos de dicha "hazaña": Eduardo Morales Miranda.

\section{Hacia una "provincia pedagógica"}

Nacido en Constitución el año 1910 en el seno de una familia de raigambre mesocrática, Morales llega a Valdivia en 1939 atraído por un proyecto inédito: la puesta en marcha de un hospital regional abierto a toda la población y servido por profesionales a jornada completa. Resulta claro -como lo atestiguan diversos académicos fundadores de la Universidad Austral de Chile $^{7}$ - que este contexto fue el légamo para concebir un proyecto de universidad para Valdivia, por cuanto allí se concentraron no sólo profesionales, sino especialistas con una alta formación universitaria y una producción científica creciente. No obstante, dichas condiciones no explican por sí mismas la alteración de un statu quo que, como un consenso involuntario, había anestesiado las fuerzas para establecer una casa de estudios superiores en el sur de Chile.

Según recuerda el ex académico Samuel Rodríguez $R$.

Correo de Valdivia, 24 de abril de 1965.

Véanse los testimonios de Italo Caorsi, Rubén Saldías y Claudio Zapata en Van de Maele (1996). 
Los empeños organizados entre 1940 y 1941 desde la Intendencia de Valdivia, los de Otto Lenck y un grupo de 12 a 15 personas hacia 1942 (Cfr. Contreras 1997), o los del escritor Fernando Santiván desde su condición de periodista del Correo de Valdivia -y presididos por otro médico-, habían sido abortados entrando la década del 50. Hacia 1952, aupado por la Sociedad de Amigos del Arte, sus amigos médicos, y con el acicate de la aparición de otro proyecto levantado por un grupo activo que quería establecer una sede de la Universidad de Chile ("Centro de Amigos de la Universidad", liderados por otro médico, Víctor Crass), Morales aparece urgente, sagaz e impetuoso con la iniciativa de fundar una universidad propia, autónoma y descentralizada (ya de la Universidad de Chile, ya de la de Concepción o de otra confesional, de origen norteamericano, que había mostrado cierto interés en establecerse en Valdivia, según recuerda el propio Morales).

Jorge Millas, Director de las Escuelas de Temporada patrocinadas por la Universidad de Chile, las que habían congregado a una parte de la comunidad valdiviana en torno al proyecto de "sede" universitaria, recuerda este momento embrionario, donde un Morales de "mirada en extremo límpida e inquisitiva" le comenta el proyecto de fundar en Valdivia una universidad. "Por supuesto, a mí me pareció absurdo y me sobraron las razones para demostrarle lo razonable que yo era", narra Millas (1979: s/p). "El vecino se levantó entonces, y con una sonrisa aún más acentuada me dijo textualmente: "Bien, director, veo que he venido por lana y he salido trasquilado". Más tarde comprendí que esta frase de Eduardo Morales no era de acatamiento, sino de desafío" (Millas 1979: $\mathrm{s} / \mathrm{p})^{8}$. En efecto, para entonces el protagonista de estas remembranzas parecía desafiar a muchas fuerzas gravitatorias que veían el proyecto como un afán iluso, una atomización de esfuerzos para lograr la más factible Sede de la Universidad de Chile ${ }^{9}, y$, también, desafiaban a un número importante de odiadores "monográficos" que lisa y llanamente se oponían a su liderazgo y sus acciones para ejecutar la idea. "¿Qué hacer con los que me combatían? Pues el número de contrincantes crecía día a día" (Morales 2004: 47), rememora el ex rector.

Aunque en esta obra él se encarga de dilucidar -sin falsa modestia- las múltiples y hábiles estrategias para aquietar los vientos contrarios y sumar energías a su quimera -resulta importante subrayar la robustez de ánimo para afrontar las variadas acciones por quebrar su voluntad-, especial atención merece -por la iteración narrativa e intención retentiva del autor- la consideración de enfermo mental o "loco" por parte de sus colegas del Hospital Regional, el asedio de los mismos derivado de sus primeras labores en la futura universidad, y, finalmente, su expulsión del Colegio Médico Regional con

\footnotetext{
En rigor y en esta etapa, Millas no sólo expresa privadamente su desacuerdo con la idea de Morales y el colectivo que lo apoya, sino que manifiesta públicamente su disenso: "Yo creo que vale la pena meditar si antes de crear la superestructura de una cierta universidad en el país no convendría ensanchar las bases de la educación fundamental [se refiere a escuelas primarias, liceos e institutos técnicos] que ha quedado a la zaga del desarrollo universitario" (Correo de Valdivia, 1 de marzo de 1954).

9 A comienzos de 1954, la polémica con el grupo liderado por el médico Víctor Crass -colega, además, de Morales en el Hospital Regional- estaba públicamente desatada. El mismo Crass exhorta en la prensa: "unamos las fuerzas para realizar lo inmediato, lo que cueste menos, lo que puede ser una realidad próxima [una sede de la U. de Chile] (...). No debemos perder esta oportunidad para Valdivia. Dejemos los grandes proyectos para un tiempo más, no quememos las etapas, pues nos quemaremos nosotros y, lo que es peor, el futuro cultural de la ciudad" (Correo de Valdivia, 28 de febrero de 1954).
} 
la prohibición de ejercer la profesión ${ }^{10}$. Más allá de la opacidad de estos hechos y de que contemos sólo con su testimonio -reelaborado, además, retrospectivamente-, parece claro que estos ataques sólo fortalecieron la ya demostrada reciedumbre de carácter y firmeza de propósitos. Fue así que Morales no duda -siempre en un contexto dialógico- en hacer frente públicamente a sus detractores, incluso invitándolos a comparecer en el seno de la universidad para que den cuenta de las críticas a su gestión o a la propia casa de estudios recién fundada ${ }^{11}$. Su empeño es metabolizar las diferencias y el conflicto para encausar, pues, esas energías, y ejecutar objetivos mayores.

Si bien parece obvio, debemos recordar que esta "quinta columna" o frente de oposición interna -en la ciudad y a poco andar, en la propia universidad-, convivía a la par con diversas fuerzas externas que se veían amenazadas con la emergencia y la consolidación de una universidad en el sur de Chile. A los imaginables escollos de orden jurídico, orgánico, económico, de masa crítica docente, infraestructura, entre muchos otros (Morales los pormenoriza vivamente), se suma la distancia inicial de las autoridades de la Universidad de Chile para con la instalación de una "Universidad Asociada" pero independiente (aunque la autonomía plena con aquella universidad en cuanto al otorgamiento de títulos propios será otra "cruzada" que tendrá un altísimo costo para Morales). Lo mismo ocurre con las reticencias e interpelaciones de la máxima

10 Quizás estos, como otros episodios, le hacen expresar en una última entrevista radial concedida en 2010 que "Valdivia no apoyó. No creyeron que se podía hacer". En línea, disponible en: http://noticias.uach.cl/ (visitado el 20 de febrero de 2014).

11 Tal como consta en las actas institucionales (Archivo Secretaría General UACh) autoridad de la Universidad de Concepción, Enrique Molina, en las que el rector fundador no profundiza en sus memorias, pero que las fuentes examinadas se encargan de completar. Molina, por ejemplo, además de mostrarse preocupado por la creación de una Lotería Valdiviana que hiciera menguar los ingresos que recogía vía impuesto la universidad penquista (Cfr. Morgado s/f), lo inducía a denominar a la recién fundada institución "Universidad de Valdivia" y no "Austral" pues competía con la presencia precedente de su universidad en el sur de Chile ${ }^{12}$. Todo ello ocurre en una coyuntura económica nacional en extremo desfavorable (crisis inflacionaria), que hacía inviable una apoyo material directo del Estado, lo que con claridad le expresa el propio Presidente lbáñez al Directorio de la UACh en un telegrama fechado el 22 de febrero de 1954: "la precaria situación de Hacienda Pública que ustedes conocen hacen que por el momento el gobierno sólo pueda limitarse a prestar a Uds. su más amplio apoyo moral"13.

Frente a estas adversidades y situado en un contexto coercitivo -regional y nacional-, pareciera que los horizontes de posibilidad de una vida para alterar las correlaciones de fuerza y sus determinantes quedarían atrapadas en el corsé de sus limitaciones. En el caso de su aspiración, a Morales le tocaba esperar resignado a que el "Estado Docente" metropolitano adquiriese suficiente musculatura para llegar por sí mismo con universidades o sedes a los espacios provinciales, tal como ocurrió de forma progresiva entrada la década del 60. "El progreso centrípeto atrofia al

12 Así consta en el telegrama del 2 de febrero de 1954 del rector Molina a Eduardo Morales (Archivo Secretaría General UACh).

13 Telegrama del Presidente Ibáñez al Directorio UACh (Archivo Secretaría General UACh). 
progreso centrífugo" reclama para entonces Morales ${ }^{14}$, e insiste contumaz en hacer de Valdivia una adelantada y descentralizada "Provincia Pedagógica": "Yo no compartía la idea de que la universidad dependiera de la sede central porque eso restaría autonomía a la provincia y no representaría en ningún momento las inquietudes de los provincianos. Una institución de esta especie acentuaría el centralismo, al cual me oponía decididamente" (Morales 2004: 23).

Consecuentemente -de ahí su singularidad-, en un ejercicio de fineza micropolítica Morales pareciera mensurar y rastrear, a medida que avanza en sus objetivos, la pérdida de capital social derivado de sus opositores organizados, para apresurarse en subsanar -ya de forma planificada o de la mano de su propia sociabilidad amical e intelectual- dichas mermas, y compensarlas en su lugar con la suma de otras adhesiones. Sus grandes aliados -como el propio Presidente Carlos Ibáñez del Campo, el Senador Carlos Acharán Arce, industriales de origen germano, empresarios agrícolas, destacados profesionales, autoridades comunales de Valdivia y de las antiguas provincias de Llanquihue y Chiloé, o el "Círculo Valdiviano de Santiago"- van siendo imantados lenta pero decididamente por sus objetivos, en la medida en que Morales construye una épica que evidencia progreso y ejecución de sus propósitos, pero siempre adaptada al flujo de intereses de sus distintas audiencias.

Se trata de una épica versátil y mudable que incluso es capaz -como él mismo narrade obliterar, si el momento lo ameritaba,

\footnotetext{
Según recuerda el ex académico Samuel Rodríguez R.
}

las "aspiraciones no confesadas", como la "autonomía de las provincias" o el carácter de su propia idea de universidad, que se adapta en un principio al sentir de la opinión pública regional, a las preocupaciones de los gremios y representantes políticos de las otras provincias del sur, y a los intereses gubernamentales ${ }^{15}$ y universitarios de Santiago y Concepción, en tanto institución volcada a resolver casi exclusivamente las necesidades productivas sureñas -especialmente silvoagropecuarias-, territorializada y con un acendrado cariz profesionalizante ${ }^{16}$. Estas son características alejadas largamente de sus definiciones, como queda de manifiesto en el innovadory ambicioso proyecto universitario que finalmente emprende en su rectoría, cuyo recuento podemos conocer en su libro. De hecho, una parte de estas concepciones sobre la universidad ha sido actualizada en de uno de los últimos registros audiovisuales de su persona, donde sentencia: "¿Una universidad para Valdivia? No. ¿Una universidad para Chile? No. Una universidad para el mundo". Luego volveremos sobre ello.

En esta dirección, conviene reparar sobre otro hábil movimiento micropolítico de orden "interno" por parte de Morales, que tiene como objetivo sumar apoyos simbólicos y materiales de la colonia alemana, especialmente de sus

15 Al respecto son ilustrativas la carta de Morales al Ministro de Educación fechada el 29 de julio de 1954, y la misiva al Presidente de la Sociedad Agrícola y Ganadera de Osorno fechada el 29 de octubre de 1954 (Archivo Secretaría General UACh).

16 Por ejemplo, en medio de las difíciles gestiones para lograr que el edificio de la familia Haverbeck Skalweit pasara a la Universidad Austral (por disposición de los dueños de esta sociedad naviera el inmueble pasaría al Municipio si es que el grupo liderado por Morales y el liderado por Crass no llegaban a un acuerdo), Morales logra tanto que el alcalde, el intendente y regidores apoyen el traspaso del edificio a la UACh, haciendo hincapié en la necesidad de entender la universidad como una entidad inserta en las actividades portuarias, metalúrgicas de astilleros, fabriles y comerciales de la región (Cfr. Morgado s/f). 
industriales, empresarios y profesionales. Aunque su participación activa en la Sociedad de Amigos del Arte lo habían acercado a variados y conspicuos descendientes germanos -donde su esposa, Carmen Verdugo, tuvo un rol protagónico- ${ }^{17} \mathrm{y}$ es invitado tempranamente al "Deutche Verein Unión" -el club germano de empleados, no el de industriales-, las fronteras y relaciones interculturales desde su arribo a la ciudad habían estado signadas experiencialmente por el prejuicio y el estereotipo. "Llegué allá y era el indio. Incluso pensé que el gobierno debía intervenir para quitarles todo el poder a los alemanes. Eso me dolió mucho"18, relata en una de sus últimas entrevistas en 2010. En estas remembranzas se comprende esta tensión: "Primer médico indio que aparece a saludarme" (Morales 2004: 19), le había espetado un reputado médico germano descendiente, con una clara intención xenófoba y racista. Con todo, Morales constata que parte de la dinamización económica, social y cultural está en manos de un colectivo de personas que "nacían en la Deutsche Kranke Hasee, se bautizaban en la Deutsche Kirche, estudiaban en la Deutsche Schule; hacían vida social en el Deutsche Verein y finalmente los enterraban en el Deutsche Friedhof" (Morales 2004: 18). De esta forma, y en medio de "una clara separación, no siempre evidente, entre la "colonia alemana" y la "colonia chilena"" (Morales 2004: 18), desplaza los contornos etnocéntricos -propios y ajenos- para fungir como un gozne mediador, articulador $y$ catalizador de las energías multiculturales que

17 La labor de Carmen Verdugo Binimelis en esta etapa fundacional resulta gravitante, especialmente en la búsqueda de apoyos civiles y políticos en la sociedad valdiviana (Cfr. Baltra 1977). Es ella, por ejemplo, quien suma tempranamente a la causa de la UACh a un decisivo adepto, el Senador Carlos Acharán Arce.

18 Entrevista radial al ex Rector Morales. En línea, disponible en http://noticias.uach.cl/ (visitado el 5 de diciembre de 2013). se habían asentado en la región -mapuches, españoles, germanos y chilenos-; labor ardua e inusual, pero fructífera tratándose de una empresa como la que se acrisolaba.

A los aportes monetarios, inmobiliarios e incluso en especies menores -"huevos, pollos, corderos, vacas" apunta Morales- conseguidos "casa por casa", se le sumará uno cardinal y permanente. El propio contexto de expansión del "Estado Docente" -que hasta entonces le había jugado en contra- $^{19}$ le abre al rector fundador un intersticio insospechado de libertad para revertir sus limitaciones: su principal aliado, Carlos Acharán Arce, logra en medio de las discusiones parlamentarias sobre financiamiento universitario conseguir el apoyo necesario para introducir en su articulado una asignación permanente para la recién creada $U A C h^{20}$, lo que posibilitó una "infancia" y un crecimiento saludable de la Corporación en el marco de muchas precariedades iniciales. Así, contra todo augurio

Dicho contexto -político, ideológico y discursivo- había erosionado inicialmente el proyecto de Morales y su grupo, puesto que sus contendores organizados argumentaban que la iniciativa se oponía a los principios de la educación pública promovida y protegida por el Estado, en cuanto intento de vulnerar el Estatuto de 1931 que confería a la Universidad de Chile la facultad de organizar los planes de estudios y de otorgar títulos y grados académicos (Cfr. Correo de Valdivia, 22 de febrero de 1954).

20 Se trata de la ley 11.575. Ello significó que la UACh obtuviera un dieciochoavo de los fondos destinados a todas las universidades producto de los impuestos, vale decir, 100 millones de pesos al año durante 20 años, más una autorización para contratar uno o más empréstitos por otros 100 millones. El senador, además, consigue otros importantes aportes del Estado a través de otras leyes, a saber, la de sueldos a los trabajadores universitarios y la Ley de Loterías (Memoria Directorio UACh, 1955-1956: 3-4, Cit. en Archivo Secretaría General UACh). Aunque Acharán Arce lidera las iniciativas, éste tiene el soporte político de una gran cantidad de personas "aliadas" (véase como ejemplo la carta al Senador del Partido Radical Marcial Mora y la copia de la "carta tipo" enviada a los demás parlamentarios del Partido Radical por el entonces Secretario General Fernando Santiván). Una revisión exhaustiva de esta discusión legislativa y su inscripción en un proceso mayor en torno al origen de la UACh y la noción de "Estado Docente" véase en Almonacid (2014). 
y sujeción, la figura institucional de la nueva universidad no sólo germina el 7 de septiembre de 1954 a través de un Decreto Presidencial, sino que emprende su consolidación con un aporte directo y estable del Fisco.

\section{Una identidad controlada: La construcción de una universidad humanista}

En estos escritos autobiográficos se encuentran los orígenes y fundamentos de las marcas de identidad que aún distinguen a la Universidad Austral de Chile-desde el propio nombre y lema, pasando por su himno, bandera y escudo, hasta la conformación de su patrimonio material-. Se sitúa también el ínterin de las arrojadas decisiones e incansables gestiones para alinear a una diversa y amplia gama de colectivos y autoridades en pos de su proyecto, arropadas, además, con un anecdotario rico en calidad e intensidad narrativa. Pero, por sobre todo, en la fragua de estos escritos se cuelan con nitidez las bases ideológicas que Morales impregnó a la institución y que la puso -a mediados del siglo XX- en la vanguardia de las universidades chilenas. De esta manera, podemos aproximarnos a interrogar estas remembranzas -inscritas y subjetivadas en la vida de Moralesprofundizando en su "sentido" en la doble acepción del término: como "significado" y "dirección". Así, nos es posible adentrarnos en el vórtice intelectual desde donde Morales sustenta en estas memorias el "sentido" de su modelo de universidad, y las peculiaridades de su decir y pensar en torno a ella.

Decisivos al respecto resultan los episodios formativos, que moldean su carácter combativamente antisectario, pero también, conforman sus sólidas convicciones, rigor y amplitud intelectual. Un papel crucial en su educación "integral" de estudiante universitario la tiene el célebre Alejandro Lipschütz, quien siendo

judío, ateo y comunista y yo católico y de tendencia social cristiana, jamás oí una palabra contra mis ideas y, muy por el contrario, siempre que conversábamos sobre temas de esa naturaleza, él decía: «Sr. Morales, usted debe profundizar en sus ideales para adquirir fortaleza y llegada la ocasión, ¡defenderlos!» (Morales 2004: 101).

Con Lipschütz, autor de un influyente ensayo sobre la idea de la universidad (La función de la universidad de 1955), sus lecturas sistemáticas de los clásicos y su actitud abierta al intercambio crítico de ideas -en especial con el ex decano Eleazar Huerta, los filósofos Adolf MeyerAbich, Jorge Millas, el ensayista Luis Oyarzún, entre otros-, Morales forjó y se empapó de un modelo universitario que se oponía con ahínco a una educación profesionalizante, que reducía su acción pedagógica a la entrega de títulos sin transmitir al estudiante el cultivo de los más amplios saberes. Siguiendo a Séneca -“¿De qué sirve la instrucción si no hace más que alimentar el orgullo y no corrige ningún defecto?"-, Morales intenta plasmar pioneramente los modelos universitarios que luchan por emerger -habida cuenta de sus fracasos y limitaciones- tanto en el país como en las más importantes universidades extranjeras, haciendo retroceder la educación pragmática, exclusiva y reproductiva, para hacer avanzar la producción de conocimiento y, especialmente, la formación integral, es decir -como titula sus remembranzas-, forjar y recuperar el maridaje "universidad humanista".

Tempranamente, y en conversación con el Ministro de Agricultura de la época, Alejandro 
Hales, el ex rector aprovecha el apoyo decidido de éste para confesar libremente su proyecto, cansado, quizás, de las sucesivas adecuaciones discursivas a las más variadas audiencias. Así, le expone que se pretenden crear

\begin{abstract}
escuelas de agronomía, medicina veterinaria e ingeniería forestal (...), pero (...) le confieso que todo ese programa es la pantalla que hemos puesto para hacer nuestro principal objetivo. Queremos terminar con el "técnico bárbaro" (...). Queremos llevar a la universidad la investigación científica en todas las ciencias básicas, queremos tener una verdadera universidad y no una de pizarrón y tiza (Morales 2004: 53-54).
\end{abstract}

Terminar con el "técnico bárbaro" supuso materializar un ambicioso plan de Morales: la Facultad de Estudios Generales, epítome de su proyecto de universidad. Esta macrounidad, en la vanguardia del modelo universitario del momento en Chile, se organizaba ofreciendo cursos comunes obligatorios de ciencias y humanidades para todo los estudiantes de la universidad $-y$ otros libres, abiertos a toda la comunidad-, con la idea futura de que congregara, además, la investigación científica producida en la UACh. Como el lector podrá apreciar en esta obra -y según consignan los propios archivos institucionales-21, ello supuso variados problemas en su implementación, pero la capitalidad de esta facultad para el corazón de la idea de universidad de Morales - de ahí que le dedique en esta obra un capítulo íntegro-, la hizo resistir diversos embates. Lo propio sucedió con la Facultad de Bellas Artes,

21 Véase por ejemplo Acta de sesión № 83 del 14 de marzo de 1958 del Consejo Universitario, sobre el reclamo del Decano Rudloff a propósito de lo que considera "la imposición" en las jornadas de la mañana de tres ramos humanísticos obligatorios con 6 horas semanales a los estudiantes de último año de todas las carreras (Archivo Secretaría General UACh). aunque con una suerte algo distinta. Formar "elites espirituales" fue su empeño, por cuanto éstas se distinguían de las "elites del dinero o de las que pretenden afianzarse en tradiciones puramente sanguíneas" (Morales 2004: 31), debido a que las primeras "nunca pierden de vista que su misión es servir a sus semejantes y jamás explotarlos como siervos del poder político o económico" (Morales 2004: 31). El 25 de julio de 1957, en un discurso pronunciado en el Salón de Honor de la Universidad Chile, Morales expone algunos resultados de su modelo:

\begin{abstract}
Creemos que el mayor aporte que la Universidad [Austral] ha hecho en favor de este grupo selecto de jóvenes - hoy en el tercer año de su carrera- es justamente el haberlos ligado a una gran empresa de bien público, de manera que, por vía de la acción personal y del ejemplo, están incorporados a un régimen de vida de alto rango, del cual se han desterrado el egoísmo, los intereses pequeños y de grupo, el arribismo y la complacencia moral (Morales 1957: 12-13).
\end{abstract}

Junto con estas ideas matrices que Morales demuestra en proceso de materialización, se deslizan en este libro de memorias una serie de postulados -colmados de maticesen torno a la universidad como institución y como organización, de enorme vigencia en nuestros días. Una intensa discusión en el Consejo Universitario con Eleazar Huerta sobre la gratuidad de la enseñanza superior, revela el espesor de las nociones y reflexiones sobre la educación como un derecho, y en torno a la universidad en las antípodas de una entidad bancaria, cuestión en la que insiste a guisa de la creación de universidades privadas a partir del año 1981. Lo propio ocurre con su defensa irrestricta de la condición pluralista y a-confesional de la casa de estudios, donde se respetasen "todas las ideas o ideales, siempre 
y cuando, disfrazándose de libertarias, no fueran dictaduras de cualquier color" (Morales 2004: 67). En la universidad -plantea Morales"no cabían los dogmatismos" (2004: 67).

Es probable -como se narra- que el autor de estos recuerdos se viera profundamente afectado por diversas exclusiones sectarias de orden político, gremial y religioso en los espacios educativos y laborales donde transitó, debido a lo cual, con la misma fuerza que combate la "beatización" o la introducción de cualquier credo religioso en la gobernanza universitaria, se opone a cualquier tipo de politización partidaria en la UACh. Ello es refrendado no sólo en esta obra y en los documentos institucionales que el mismo Morales cita en ella, sino también en diversas actas del Consejo Universitario que hemos investigado. En una de éstas, por ejemplo, se registra una carta que el rector fundador leyó ante los consejeros a propósito de "el papel que corresponde en la política al profesor universitario"22. En la misiva, Morales realiza la distinción entre política y política partidaria y, a su vez, entre política y "alta política", argumentando sobre el sacrificio necesario de la abstención en la política partidista del profesor universitario, "en la medida que no se compadece con la inquieta y absorbente actividad del hombre politizado; ni la dignidad de la cátedra, con el griterío de las asambleas o de los desfiles callejeros"23. "No obstante -concluye-, hay un terreno del que el ciudadano no puede abdicar sin deshonor: el de la alta política. Debe pues el maestro velar porque los derechos fundamentales del hombre

22 Acta sesión Consejo Universitario $N^{\circ} 152$, martes 2 de septiembre de 1958.

3 Acta sesión Consejo Universitario $N^{\circ} 152$, martes 2 de septiembre de 1958. no sean lesionados, y justa es su inquietud para elegir a los mejores gobernantes"24.

Ello nos permite entender una parte importante de las cavilaciones y episodios biográficos en los que se enfrenta a las fricciones entre la universidad como institución -históricamente forjada- y organización -coyunturalmente construida-, donde las prácticas políticas -"altas", medianas o bajas- encuentran cabida. Así, Morales se muestra dubitativo de la universidad concebida como una "república" entregada a la voluntad de un "demos" universitario vago o impreciso. El propio proceso eleccionario donde es reelegido como rector, junto con una serie de conversaciones con las directivas de los partidos políticos valdivianos, componen un recuerdo que cuestiona frecuentemente la naturaleza de la participación política -partidista o no- interna y externa del profesorado y el estamento estudiantil. Todo ello en un contexto -debemos precisarlodonde existía en el Consejo Universitario (homólogo al actual Consejo Académico de la referida institución) la presencia de dos representantes de la Federación de Estudiantes con plenos derechos ${ }^{25}$. Aún reflexivo sobre la naturaleza de la participación y la ciudadanía universitaria, Morales, muchos años después y enfrentado a los rectores delegados por la dictadura militar, se muestra sin titubeos y con extrema claridad: "Yo le manifesté al General Palacios que el gobierno militar podía mantener la estructura de la Universidad, pero de ninguna manera acrecentar el espíritu que la informaba. La autoridad militar es vertical, la autoridad

\footnotetext{
24 Acta sesión Consejo Universitario N 152, martes 2 de septiembre de 1958.

25 Excepto cuando se decidiera sobre el personal docente y administrativo (Cfr. Almonacid 2003)
} 
académica es horizontal; en la primera, se obedece y en la segunda, se discute" (Morales 2004: 196).

\section{A modo de conclusión: Una heterobiografía en primera persona}

Parte de la "ilusión biográfica" -en la que Pierre Bourdieu también repara- es el espejismo de causalidad, orientación y linealidad de gran parte de la retórica (auto)biográfica, en la medida en que una porción importante de este tipo de obras aparece como reconstrucciones a posteriori de coherencias factuales, vale decir, relatos sobre la existencia individual enmarcados en el acontecimiento predecible y ajustado a las circunstancias del narrador. Estas remembranzas no se escapan, aunque tampoco buscan rehuir, de aquello. No hay aquí una muestra copiosa de las contradicciones decisionales o la autoconciencia de la entropía de la vida, o evidencia de que la coherencia del bios es el biombo de una miríada de fragmentos, astillas o girones de la identidad, cuya constancia es improbable como un sujeto fijo en un mundo movedizo. No. Lo que Morales emprende en esta obra es la construcción de eslabones que encajan uno a uno para sostener un fin -ya como proyecto, ya como final-. De ahí se entienden, entre otros acoples, su temple e indocilidad autoatribuida a un episodio de "castigo" en la infancia o su antisectarismo ligado a su experiencia como estudiante adolescente, lo que signa, a su vez, su relación con la política, la religión y sus banderías dentro y fuera del espacio universitario. De esta manera, no resultará extraño encontrar muchos conectores argumentales en la cronología de su vida que explican la continuidad y la causalidad de ésta y también la de los demás, como la voluntad de modestia y resignación ante los reveses ayudado por el místico y canónigo Agustino Tomás de Kempis ("Que la gloria de este mundo no te envanezca"), o las actitudes siempre beligerantes y "problemáticas" de los colegas universitarios a partir de una temprana y recurrente advertencia de su maestro Alejandro Lipschütz: "científicos, médicos y artistas son pequeños dioses".

Ahora bien, lo anterior se comprende por la naturaleza del género biográfico ${ }^{26}-y$ también por el tipo de (auto)biografía que emprende-, habida cuenta que funde y fija en una "identidad contada" su itinerario vital con la propia trayectoria institucional. Su autodefinición como "un hombre ejecutivo, el que hace cosas inmediatamente después de decidir sobre ellas" (Almonacid 2003: 194), realizada antes de ordenar y componer estas remembranzas, revela -al menos- el objetivo de cifrar un régimen de verdad sobre sí mismo anclado en la resistencia al infortunio, a las adversidades y a la inmovilidad, que son especulares a lo acaecido en el bios de infancia de la propia universidad. Por ello, recíprocamente, es en la forja de la institución donde Morales encuentra su identidad más estable y decible, tanto que pareciera convenir con J. L Borges que "cualquier destino, por largo y complicado que sea, consta en realidad de un solo momento: el momento en que el hombre sabe para siempre quién es" (1998: 62). Ilusión o espejismo, parte del "efecto biográfico" -de su retórica y de su gramática- es precisamente la elaboración de un sí mismo que resulta unitario -constante y

Para muchos, "incestuoso", producto de la promiscuidad entre lo ficcional y lo factual, "indeterminado", en la medida en que toda escritura es autobiográfica (Cfr. De Man 1991), o lisa y llanamente, un género "minusválido de la historia", como lo planteó el historiador francés Marc Ferro (1989). 
persistente-, y que pareciera resistirse a los cambios. Se trata de una escenificación casi intemporal del yo en los otros, una dramaturgia de la identidad que sólo se renombra en el presente de la escritura, hasta quedar en paz. Es un "efecto" que el autor no elude, más bien abraza.

Consecuentemente, uno de los primeros elementos para "dejarse recorrer" por estas evocaciones es el andamiaje y el horizonte de expectativas con las que se elabora. Morales tiene autoconciencia de su figura como soporte axialdel "dramahistórico" quesupusola creación de la universidad. Dicha autoconsciencia se nutre de las memorias (oficiales y no oficiales) acumuladas y diseminadas, que lo saben artífice y protagonista singular de la "gesta": "Sólo hay un hombre en varios millones que puedan decir como Ud.: 'he creado una universidad'" (Morales 2004: 208), le recuerda decir al profesor José Balen. En la misma línea, en las Actas de Memorias del Directorio se puede leer a propósito de los rápidos logros de su rectoría:

Su carácter absorbente lo impele a mezclarse en todo: en las grandes y en las pequeñas empresas. Tan pronto discute con hombres de Gobierno y con los dirigentes de la Universidad máxima de Chile, como interviene en el nombramiento de un mozo o de un portero; ya proyecta audaz reforma pedagógica y elabora o adapta Reglamentos de Facultades, ya controla el uso del papel gastado en una oficina y dispone la ubicación de las lamparillas de una sala. Su actitud no conoce límite y todo lo traspasa $^{27}$.

27 Memoria Directorio UACh 1955-1956: 5, Cit. en Archivo Secretaría General UACh.
La consecuencia de ello es que se autoimpone la factura de una autobiografía multivocal, construida por su mano y sus memorias, pero también que abreva de la memoria oral y colectiva $-y$ sus diversos tamices-, actas, discursos, cartas y archivos institucionales. Ahora bien, lo peculiar de esta coralidad biográfica es que una parte significativa de la "primera voz" está recogida del conjunto de testimonios que la periodista Lidia Baltra (1977) registró en sucesivas entrevistas con Morales para componer el libro Nace una universidad. En aquel libro, Baltra confecciona una crónica histórica de los inicios de la UACh basado en los recuerdos del rector fundador, la mayor de las veces parafraseándolo y otras, citándolo textualmente. En la presente obra, Morales (2004) recopila una parte del material original, lo reescribe, profundiza, desarrolla y reinterpreta, quitándole de paso la tesitura hagiográfica de esos testimonios para que la vida -más allá de los efectos de solidez y coherencia-, quede con las costuras a la vista y se muestre en toda su fragilidad. El resultado -inusual en los procedimientos utilizados canónicamente en el género- es la superposición de estratos autorales, lo que la convierte en una distintiva "heterobiografía" en primera persona.

Por otra parte, y como decíamos, una fuente cardinal de sus "remembranzas" son los registros institucionales. Estas fuentes le sirven para ilustrar, argumentar o justificar la veracidad y razón de sus asertos y acciones, en trances siempre difíciles para quien tiene la más alta responsabilidad por la marcha de la universidad. Hacia el final, las memorias toman un rumbo precipitado y atomizado acorde, quizás, a los acontecimientos que allí se narran: la renuncia forzada a la rectoría y presidencia de la UACh. Aunque no es 
menester detallar este trance, inscrito en un "agotamiento de la política universitaria"28 en pos de conseguir la autonomía plena, se advierte que la luz cenital que cae sobre él se desplaza, ayudado, precisamente, por estas fuentes escritas. Aparece así-y con un abultado guion- un Eduardo Morales descentrado por un antagonista al que le da un ancho espacio de expresión, aguijonado, posiblemente, por el afán de documentar un modo dialógico de veracidad histórica. Con todo -y esa es una de las provocaciones que instala como "efecto" en esta obra-, su empresa no es retrospectiva, sino prospectiva, pues se empecina por anunciar un futuro. El trabajo de su memoria, como política del presente, se arriesga sin tapujos a ponderar sus limitaciones pasadas y, más allá, a imaginar otra universidad posible.

\section{Bibliografía}

Almonacid, F. 2014. Los desafíos de creary sosteneruna universidad regional: Pasado y presente de la Universidad Austral de Chile. Clase magistral de inauguración del año académico 2014. Campus Patagonia, Coyhaique.

2003. Historia de la Universidad Austral de Chile 1954-2003. Valdivia: UACh.

Araya, O. 2011. De vértebras, lecciones y sueños. Acopio de memorias de una travesía: La Facultad de Ciencias Veterinarias de la Universidad Austral de Chile (1954-2010). Valdivia: UACh.

Baltra, L. 1977. Nace una universidad. Santiago: Autoedición.

Borges, J. L. 1998. "Biografía de Tadeo Isidoro Cruz (1829-1874)". El Aleph. Borges, J. (Autor). Madrid: Alianza Editorial. En línea, disponible en: http://www.literatura.us/ borges/biografia.html

Bourdieu, P. 2004. Esquisse pour une auto-analyse. París: Raisons d'Agir Éditions. 1997. Razones prácticas, sobre la teoría de la acción. Barcelona: Anagrama. 1986. "L'illusion biographique". Actes de la Recherche en Sciences Sociales 62/63: 69-72.
Contreras, R. 1997. Algunas ideas valdivianas en la creación de la Universidad Austral de Chile. Valdivia: UACh.

De Man, P. 1991. "La autobiografía como desfiguración. La autobiografía y sus problemas teóricos". Anthropos 29: 113-114.

Ferro, M. 1955. "La biographie, cette handicapeé d'I'histoire". Le Magazine Lettéraire 164: 85-86.

Lipschütz, A. 1955. La función de la universidad. Santiago: Nacimiento.

Millas, J. 1979. Discurso de homenaje al rector fundador Eduardo Morales ante el senado universitario. Valdivia: Archivo Secretaría General UACh.

Morales, E. 2004. Remembranzas de una universidad humanista. A 50 años de la fundación de la Universidad Austral. Valdivia: Autoedición.

1957. La nueva Universidad Austral de Chile.

Santiago: Imprenta Editorial del Pacífico.

Morgado, F. (s/f). Fundación de la Universidad Austral de Chile: Historia para ser contada, leída y meditada. Valdivia: Archivo Secretaría General UACh.

Van de Maele, P. 1996. La isla del alma mater. Historia testimonial de una universidad. Valdivia: Autoedición.

28 Según consigna el Libro de Actas de Reuniones Generales (19541963: 195-197) del 23 de febrero 1962, que registra las sesiones conjuntas del Directorio y del Consejo Universitario, donde se hace referencia a las causas de la renuncia de Morales. Se registra allí el fracaso de las gestiones por lograr la aprobación de un cuerpo legal que otorgara la autonomía de la UACh para otorgar títulos y grados (Archivo Secretaría General UACh). 
